\title{
Ruhe zur Verbesserung der Energiebilanz?
}

Andreas Pestalozzi

Korrespondenz:

Dr. med. Andreas Pestalozzi Kawazen 7

CH-8536 Hüttwilen

pestalozzi.huettwilen@hin.ch

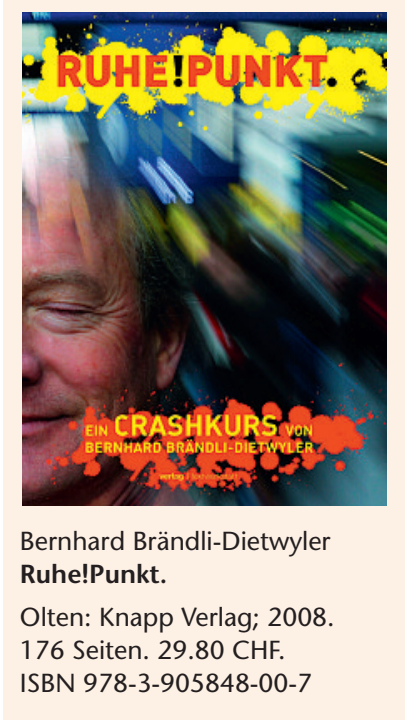

Das Buch «Ruhe!Punkt.» von Bernhard Brändli-Dietwyler legt den Finger auf die ständige Betriebsamkeit unserer modernen Gesellschaft. Durch die Illusion, dass Immer-Aktivsein bedeutet, besonders viel vom Leben zu haben, nehmen wir gesundheitlich Schaden, weil wir mit unserer Energie nicht richtig haushalten. Getrieben von Gier merken wir nicht, wie wir dadurch an uns selbst Raubbau treiben.

Der Autor ruft auf zum Innehalten - zum zur Ruhe kommen -, immer wieder, mehrmals täglich, um in der Ruhe wieder Energie aufzutanken für die nächste Aktivitätsphase. Er nennt es Ruhepunkte: winzige, wenige Sekunden dauernde und kleine, nur wenige Minuten dauernde Timeouts, mittlere Liegepausen (zum Beispiel Mittagsruhe) und grosse, das heisst genügend Schlaf ( 8 bis 10 Stunden). Für jeden und überall sei dies durchführbar, man müsse es sich aber gegen eigene und äussere Widerstände hart erkämpfen. Bernhard Brändli verspricht bei regelmässiger Anwendung eine bessere Gesundheit und grössere Lebensqualität. Durch kluges Energiemanagement mit Ruhepunkten sei man täglich in Bestform und fähig zur konstanten Hochleistung («Fünfer und 's Weggli»).

Das Buch ist aus einem Seminar entstanden, der Untertitel heisst denn auch «Ein Crashkurs». Es liest sich leicht und macht sicher jeden Mediziner betroffen. Nach einer epischen, schonungslosen Darstellung der negativen Folgen unserer hektischen Lebensweise im individuellen wie gesellschaftlichen Bereich ist das Buch dann persönlich herausfordernd, zum Teil auch apodiktisch («Die Natur fordert eine tägliche Energiebilanz, in der das Verhältnis zwischen Aktivitäts- und Ruhephasen 1:1 ist»).

Gewiss - Ruhen ist eine Lebensnotwendigkeit. Gerade auch in unserer westlichen Medizin, inzwischen eine der stressigsten Branchen, ist regelmässiges Innehalten nötig, um nicht in sinnlosen und gefährlichen Aktivismus zu verfallen und um die ethisch richtigen Entscheidungen zu treffen.

Aber - die Idee der Ruhepunkte allein greift meines Erachtens zu kurz. Genügt denn Verbesserung der Energiebilanz als alleiniges Ziel? So gesehen ist das Buch eine Anleitung zur Effizienzsteigerung durch Ökonomisierung unserer Energie und damit ganz im Trend der Leistungsgesellschaft, die aber gleichzeitig kritisiert wird.

Ist Ruhe denn nicht auch Voraussetzung für Besinnlichkeit und Spiritualität, für neue Sichtweisen und Kreativität?

Darum - Ruhepunkte als notwendiger erster Schritt. Was daraus wird, darauf darf jeder gespannt sein, der sich darauf einlässt. 